\title{
La doulou
}

\author{
Erhard Taverna
}

«La doulou», provenzalisch für «la douleur», nennt Alphonse Daudet (1840-1897) seinen fragmentarischen Bericht über die eigene Syphilis im Endstadium. Der gleiche Daudet, den wir in der Schule mit seinen «Lettres de mon moulin» und «Tartarin de Tarascon» kennengelernt haben. Anfängerübungen für Französischschüler. Ein vergessener Bestsellerautor, der in Troussets mehrbändigem «Nouveau Dictionnaire Encyclopédique» Ende des Jahrhunderts schon nicht mehr erwähnt wird. Anders als die anderen grossen, syphilitischen Literaten: Baudelaire, Flaubert und Maupassant.

Daudet infizierte sich mit 17 Jahren und unterzog sich einer Quecksilberbehandlung, der eine lange Latenzzeit folgte. Von seinem Projekt eines grösseren Werkes über Schmerzen blieb nur ein schmaler Band, der erst 1930 in Paris veröffentlicht wurde. Rund 90 Seiten, die, 2002 neu aufgelegt, besonders in der englischen Übersetzung Aufsehen erregten. Die deutsche Ausgabe von 2003 mit dem Titel «Im Land der Schmerzen» gibt den Juroren der «Times» recht.

Zwar gehört eine Schmerzbeschreibung zu fast jeder Anamnese, doch haben wir unverändert Mühe, der Empfindung eine Sprache zu geben. Der Romancier und Journalist ist kein Märtyrer, der pathetisch seine Wunden zeigt. Er ist bis zum Lebensende ein Geniesser, ein Lebemann, der seinem Leiden mit geschliffenen Formulierungen begegnet, resigniert, verzweifelt und dennoch mit höflicher Distanz. Er weiss, dass «die Worte erst wieder fliessen, wenn alles vorbei ist, wenn die Dinge sich wieder beruhigt haben. Sie sprechen nur von Erinnerung, kraftlos oder unwahr.» Der verwöhnte Erfolgsautor und charmante Geschichtenerzähler umkreist seine Privathölle in fragmentarischen Notizen, ohne daraus ein Testament seiner Beschwerden zu machen. Dabei hilft ihm das, was er seine Persönlichkeitsspaltung nennt: «Dieses furchtbare zweite Ich ist immer präsent. Es ist, als sässe es auf einem Stuhl und beobachtete dabei, wie das erste Ich aufsteht, handelt, lebt, leidet und sich abstrampelt.» Er sucht eine Sprache für das nicht Nennbare, umkreist das Unsagbare, bohrend, suchend wie das Leiden selber. Er beobachtet, wie er sich dabei verändert, wie seine Umgebung reagiert, wie sie sich über die Wiederholungen zu langweilen beginnt, wie sie sich daran gewöhnt, während er jede Attacke neu und anders erlebt. Die Qualen schliessen ihn aus, im Land der Schmerzen ist jeder allein. Wenn die Bäder schliessen, «dann löst sich diese Anhäufung von Schmerz auf, zerstreut sich. Jeder Kranke verwandelt sich in einen Einsamen, verloren im Lärm und Treiben des Lebens, in ein befremdliches Wesen, das durch die Komik seines Leidens als Hypochonder erscheint, das man zwar bedauert, das einem jedoch auch auf die Nerven geht.» Daudet begegnet allen medizinischen Kapazitäten seiner Zeit, unterzieht sich willig allen Behandlungsmethoden, schluckt Chloral, Bromid und Morphium und nimmt Anteil an den Tragödien und den Skurrilitäten seiner Leidensgenossen und Therapeuten.

«Heute nacht hüpft der Schmerz hierhin und dorthin, wie ein kleiner Vogel-Kobold, verfolgt von der Nadel meiner Spritze, über meine Glieder, direkt in die Gelenke hinein.» Oder: «In meinem ausgehöhlten, von der Anämie entleerten Gerippe tönt der Schmerz, wie die Stimme in einer Wohnung frei von Möbeln oder Tapeten. Tage, lange Tage, an denen es nichts Lebendiges in mir gibt als das Leiden.» Er nennt sich «das Einmannorchester der Schmerzen» und tut alles, um andere mit seinen Misstönen nicht zu erschrecken. Er möchte sich verkriechen wie ein Maulwurf, «wenn man schon leiden muss, dann ist das einzig Wahre, allein leiden zu dürfen». Er denkt oft an Selbstmord und weiss: «Der Haken bei der Sache ist nur, dass diejenigen, die man liebt, bereits beschlossen haben, dass man weiterleben soll - und sei es auch nur um ihretwillen.»

Daudet glaubt nicht an ein Leben nach dem Tod. Er träumt von einem Spaziergang durch Ginsterbüsche. Überall hört er das Geräusch aufplatzender Samenhülsen. Letztlich, so folgert er, sei unser Leben nicht mehr als dies - das leichte Knistern aufplatzender Hülsen.

Daudets Tapferkeit beschämt, die Brillanz seiner Texte ist bewundernswert. Doch letztlich rührt uns die Vergeblichkeit seines Unternehmens, die niemand besser erkannte als er selber. - Alphonse Daudet. Im Land der Schmerzen. Eingeleitet und kommentiert von Julian Barnes. Bremen: manholt Verlag; 2003. 